\title{
Intersetorialidade, Convergência e Sustentabilidade: Desafios do Programa Bolsa Família em Manguinhos, RJ
}

\author{
Intersectoral, Convergent and Sustainable Actions: \\ The Challenges of the "Bolsa Família" Program \\ in Manguinhos shantytown in Rio de Janeiro
}

Rosana Magalhães ${ }^{1}$

Angela Virginia Coelho ${ }^{1}$

Milena Ferreira Nogueira ${ }^{1}$

Cláudia Bocca ${ }^{1}$

${ }^{1}$ Escola Nacional de Saúde Pública, Fiocruz. Rua Leopoldo Bulhões 1480, Bonsucesso. 21041-210 Rio de Janeiro RJ. rosana99@uol.com.br

\begin{abstract}
Some studies have revealed the impact of the family welfare allowance based on the fulfillment of certain conditions on improving living conditions and access to health and education services in different countries. However, gaps persist relating to the evaluation of the benefits of such programs among the groups that have greater difficulty in gaining access to public services or advances in the quality of education and school performance. Moreover, there is limited evidence of adequacy of the program to the respective contexts of implementation, levels of adhesion and local cooperation and strategies adopted for integration with other social policy programs. The scope of this article is to discuss the findings of the study of the implementation of the "Bolsa Familia" in the Manguinhos shantytown area in Rio de Janeiro conducted in 2007 and 2008 based on semi-structured interviews with program officials and local stakeholders. In conclusion, the study shows that the sustainability of "Bolsa Familia" actions to reduce poverty and promote health equity calls for strengthening the vertical and horizontal communication channels between government levels, public managers and civil associations, recognition of the complexity of the local social demands and an intersectoral agenda.
\end{abstract}

Key words Evaluation, Poverty, Health promotion, Social policy
Resumo Alguns estudos têm revelado o impacto de programas de transferência condicionada de renda na melhoria das condições de vida e no acesso a serviços básicos de saúde e educação em diferentes países. No entanto, persistem lacunas no que se refere à avaliação dos benefícios de tais intervenções entre os grupos que apresentam maiores dificuldades em acessar serviços públicos ou dos avanços na qualidade do ensino e desempenho escolar. Além disso, existem poucas evidências sobre a adequação das ações aos respectivos contextos de implementação, níveis de adesão e cooperação, local e estratégias adotadas para a integração com as demais políticas de proteção social. O artigo discute os resultados da pesquisa avaliativa sobre a implementação do programa de transferência condicionada de renda Bolsa Família em Manguinhos (RJ) realizada entre os anos de 2007 e 2008. Foram realizadas entrevistas com gestores das secretarias municipais de assistência social, saúde e educação e agentes implementadores locais. Em Manguinhos, a sustentabilidade das ações voltadas à redução da pobreza e promoção da saúde envolve o fortalecimento de canais de interlocução entre níveis de governo, gestores públicos e associações civis, reconhecimento da complexidade das demandas sociais locais e pactuação de uma agenda intersetorial.

Palavras-chave Avaliação, Pobreza, Promoção da saúde, Política social 


\section{Introdução}

A partir dos anos 80 os processos de descentralização e redemocratização e os desdobramentos do chamado "pacto federativo" trouxeram novas possibilidades e, também desafios para a implementação de políticas públicas no Brasil. Em linhas gerais, intersetorialidade, convergência e sustentabilidade passaram a ser categorias chave para a compreensão dos rumos e alcances das intervenções em cenários locais orientados pela busca de inovação e fortalecimento da gestão pública. No que se refere ao combate à pobreza e redução das desigualdades sociais, programas de transferência condicionada de renda - conditional cash transfer - surgiram nos estados e municípios brasileiros tendo como princípio estratégico a articulação entre diferentes áreas da política social como educação, saúde e trabalho. No bojo da avaliação da baixa efetividade das políticas sociais no contexto autoritário anterior e na persistência de quadros dramáticos de miséria e de destituição social setores do Estado e sociedade civil contribuíram para forjar novos consensos em torno do perfil de programas públicos. Após a década de 1990, a redução sustentável da pobreza está, cada vez mais, relacionada à capacidade de proteger os pobres contra alterações no rendimento e consumo através de transferências monetárias, mas também, a garantia da qualidade de vida das famílias.

Na tentativa de superar a tradição assistencialista e clientelista das ações na área, a transferência de renda e o acesso às políticas sociais tornam-se estratégias combinadas e articuladas. A criação do programa Bolsa Família em 2003 a partir da unificação de programas federais como o Bolsa Alimentação, Cartão Alimentação, Auxílio Gás e Bolsa Escola expressa tal aprendizado institucional, consolidando a utilização de um cadastro único como ferramenta para o mapeamento da população alvo de políticas sociais e buscando envolver, no combate á pobreza, ações na área de educação e saúde ${ }^{1}$. O Ministério do Desenvolvimento Social (MDS) é responsável pela coordenação, gestão e fiscalização das ações relacionadas à implementação do Cadastro Único (CadÚnico), pagamento dos benefícios, monitoramento das condicionalidades e oferta de programas complementares. Através da definição de duas faixas de renda mensal per capita, famílias consideradas pobres e extremamente pobres recebem os recursos monetários diretamente nas agências da Caixa Econômica Federal. De acordo com o MDS² em 2007 98,6\% dos beneficiários possuíam renda familiar mensal de até 3 salários mínimos e 69,1\% vivia na região nordeste do país. No que se refere à importância dos recursos transferidos através do programa para a economia dos municípios, o estudo de Marques ${ }^{3}$ revelou que em muitas localidades tal montante ultrapassava os valores destinados pelo governo federal ao Sistema Único de Saúde (SUS) e, também a arrecadação com o imposto de circulação de mercadorias (ICMS). Nas regiões rurais e onde o custo de vida tende a ser mais baixo o fluxo monetário foi responsável pela dinamização da economia local ${ }^{4,5}$.

No entanto, estudos realizados em diferentes regiões do país ${ }^{6,7}$ apontam para a existência de processos muito distintos de captação, cadastramento e acompanhamento de beneficiários ligados à variações na capacidade técnica e políticoinstitucional e ausência de estruturas de incentivo para a adesão em cada contexto local. Ao mesmo tempo, a fragilidade dos mecanismos de avaliação e monitoramento dificulta a análise e sistematização de evidências de efetividade e dos diferentes impactos e limites da intervenção. Cresce, assim, a importância de pesquisas voltadas ao acompanhamento de experiências locais capazes de trazer novos elementos para a reflexão sobre obstáculos, conflitos e alternativas bem sucedidas na trajetória de implementação do programa Bolsa Família no país. Neste artigo, buscamos discutir a implementação do programa em Manguinhos área localizada na zona norte do município do RJ e região marcada pela violência, desemprego e acesso precário a equipamentos públicos. Explorando a perspectiva da avaliação como "prática social e reflexiva" nosso objetivo foi contribuir para a compreensão de conexões e também pontos de afastamento entre normas e diretrizes que estruturam o programa federal Bolsa Família e o contexto e dinâmica local, identificando aspectos frágeis e alternativas possíveis para o fortalecimento das ações voltadas à redução da pobreza no país.

\section{Considerações metodológicas: aproximando processos e resultados}

O foco nos processos de implementação para além das técnicas e procedimentos empregados, busca reconhecer a complexidade da dinâmica decisória no âmbito das diferentes agências e arranjos institucionais em torno de programas e iniciativas públicas. Também está voltado á questão da "tradução" dos resultados da avaliação para o universo da gestão local, contornando confli- 
tos, divergências e obstáculos. Para Patton ${ }^{8}$ a abordagem "compreensiva" sobre processos e resultados não obstrui a análise da accountability e dos avanços do programa, mas, diferentemente do enfoque experimental é capaz de iluminar a "natureza e o significado das mudanças” ligadas às ações e iniciativas em cada contexto social.

Os estudos sobre processos de implementação de políticas e programas sociais permitem identificar quais atividades, mecanismos e estratégias adotadas contribuem para consolidar pontos fortes e contornar pontos fracos. A avaliação, preocupada apenas com resultados finais, oferece dados sobre o sucesso ou fracasso dos programas, mas a informação sobre quais foram os fluxos e escolhas que contribuíram para tais resultados permanecem pouco claros. Pressmann et al. ${ }^{9}$ reforçam a ideia de que a implementação incorpora processos de aprendizagem, adaptação e principalmente decisões políticas. Para os autores a implementação não é uma "etapa posterior à formulação", mas um momento de decisões cruciais que pode envolver diferentes atores e recursos em uma cadeia de eventos marcada por disputas de interesses. Constrangimentos e escolhas ganham destaque e rompem com a visão linear do desenvolvimento das políticas públicas. Em outras palavras, as estratégias de implementação ultrapassam princípios normativos e diretrizes técnicas e, neste sentido, o contexto concreto onde são desenvolvidas as atividades não é algo que possa ser entendido como exterior ao programa. Cada contexto local tem um horizonte de problemas e uma "constelação" própria de interesses possibilitando diferentes espaços de negociação e concertação em torno da intervenção. Com isso, na maioria das vezes, o processo de implementação de políticas públicas mostra-se complexo e obscuro. Múltiplas variáveis e influências tendem a produzir transformações e deslocamentos que escapam ao que foi planejado. Frequentemente, durante a implementação de políticas e programas, hierarquia, controle e previsibilidade dão lugar à acomodação, barganha e incerteza. O acompanhamento desta trajetória gera, assim, uma importante aproximação com fluxos onde se dão a construção de regras, a definição de papéis e, também, os conflitos de interesses permitindo, em última análise, entender se o programa é desenvolvido a partir de seu desenho original ou não. Ao mesmo tempo, como aponta Pawson ${ }^{10}$ torna-se possível detectar quais, e de que maneira são mobilizados, os recursos que irão capacitar os sujeitos da intervenção para o alcance de resultados. Tal "mecanismo" depende do contexto, dos perfis dos agentes envolvidos e da dinâmica local e, neste sentido, pode explicar os impactos e as "evidências de efetividade" distintos em cada realidade.

Nesta direção, buscando valorizar os aspectos contextuais da implementação do programa Bolsa Família em Manguinhos foi realizado um estudo de caso, estratégia metodológica que permitiu a utilização de diferentes fontes de evidência como levantamento e análise documental, entrevistas com profissionais, técnicos e gestores locais e observação direta de atividades de rotina e reuniões de avaliação. Como ressalta $Y^{1}{ }^{11} \mathrm{o}$ estudo de caso não é uma tática para a coleta de dados, mas uma "estratégia de pesquisa abrangente" capaz de explorar processos de adaptação, fluxos decisórios e alternativas que podem gerar novas pesquisas e aprendizados. No entanto, a escolha de Manguinhos como "unidade de análise" para o desenvolvimento do estudo de caso representou um desafio. Explorar o conjunto de decisões e estratégias em torno da implementação do programa Bolsa Família em um "território" dinâmico onde limites e fronteiras estão permanentemente sendo refeitas, evidenciando uma lógica de territorialização própria e que contrasta, muitas vezes, com o olhar tradicional das políticas públicas, impôs o reconhecimento de diferentes arenas decisórias, atores sociais e fluxos de informação. A relação entre a comunidade e a Fundação Oswaldo Cruz, materializada no espaço do Centro de Saúde Escola e no contato permanente com pesquisadores e alunos traziam especificidades importantes ao estudo da implementação do programa. Inovações institucionais frente às demais áreas programáticas do município conformavam um terreno aberto para experimentações e novos arranjos organizacionais. Ao mesmo tempo a interlocução com as pesquisas desenvolvidas no âmbito do Departamento de Ciências Sociais e diversos núcleos de investigação da Escola Nacional de Saúde Pública possibilitou o fortalecimento do debate conceitual e metodológico, incorporando pesquisadores e alunos do programa de mestrado e doutorado que participaram da elaboração e aplicação dos roteiros de entrevista com gestores, técnicos e profissionais. Sem pretender esgotar a riqueza desta experiência, as questões traçadas no escopo deste artigo buscaram contribuir para a discussão sobre os desafios da implementação de políticas públicas intersetoriais e do alcance de maior efetividade das ações voltadas à redução da pobreza. Segundo Junqueira ${ }^{12}$ a intersetorialidade é uma estratégia para a supera- 
ção da fragmentação das políticas públicas através da construção e fortalecimento de ações sinérgicas, troca de experiências e diálogo entre setores, organizações e atores chave. Em cada arranjo intersetorial, diferentes níveis de articulação, pactuação e cooperação entre os setores podem emergir dependendo das barreiras, possibilidades e incentivos para a convergência das ações. Na verdade, a intersetorialidade tende a envolver deslocamentos de poder e criação de compromissos em torno de objetivos comuns e, portanto, impacta a própria governança, entendida como o conjunto de instituições e processos ligados à solução de questões sociais complexas como a pobreza e a promoção da saúde.

\section{Manguinhos:}

entre o bairro e o "Complexo"

A região de Manguinhos localizada na zona norte do município do Rio de Janeiro era uma área de chácaras e fazendas até o final do século XIX. O processo de urbanização da região cresceu com a implantação da Estrada de Ferro em 1886 e, posteriormente, com o deslocamento de habitantes do centro da cidade e remoção de favelas e parques proletários localizados em áreas mais valorizadas da zona sul. Segundo dados do Censo de 2000 (IBGE) ${ }^{13}$ havia 31059 habitantes no bairro de Manguinhos e, nas áreas favelizadas ou de "aglomerados subnormais" 22475 habitantes, com um ligeiro predomínio da população feminina em relação à masculina. As comunidades mais antigas de Manguinhos, como o Parque Oswaldo Cruz e João Goulart tendem a apresentar melhores condições de moradia e de vida frente às localizadas em áreas de ocupação mais recentes. Trata-se assim, de um espaço social heterogêneo e dinâmico, onde múltiplas demandas e necessidades sociais desafiam a gestão cotidiana das políticas públicas. Sem dúvida, não há consenso sobre fronteiras e limites do território, entendido aqui como espaço social onde se confrontam as referências de pertencimento comunitário e burocráticas ligadas às diferentes instituições, órgãos e entidades públicas atuantes na região. A delimitação formal do bairro não expressa a apropriação simbólica do espaço pelos indivíduos e famílias. Ao mesmo tempo, marcada pelos confrontos associados ao tráfico de drogas frequentemente a região é também reconhecida como "Complexo de Manguinhos", em uma clara associação à linguagem policial em torno dos complexos penitenciários existentes no município do Rio de Janeiro.
Além do estigma, a população de Manguinhos enfrentava barreiras para acessar serviços e equipamentos sociais. Segundo dados do Instituto Pereira Passos (IPP ${ }^{14}$ em 2004 o índice de mortalidade infantil observado na região era de 28,6 mil nascidos vivos, ou seja, cerca de três vezes o índice considerado aceitável pela OMS (10 por mil nascidos vivos). Em relação ao ranking do Índice de Desenvolvimento Humano (IDH) municipal Manguinhos ocupava o $122^{\circ}$ lugar entre os 126 bairros pesquisados. Especificamente no que se refere à educação, a média de anos de estudo era de cinco anos, sendo que quase $70 \%$ da população com mais de 25 anos possuía menos de oito anos de estudo ${ }^{13}$. Além disso, o percentual de crianças analfabetas na faixa etária entre 7 e 14 anos em Manguinhos - 11,11\% - era quase o dobro do percentual da cidade do RJ - 5,89\%. Em 2001, o Guia de Equipamentos e Iniciativas Sociais de Manguinhos, elaborado no âmbito do programa de Desenvolvimento Integrado e Sustentável - DLIS Manguinhos ${ }^{15}$ revelou a presença de experiências voltadas à promoção de atividades culturais, lazer e esportes, sobretudo envolvendo a população jovem. No entanto, apesar da atuação de diferentes organizações não governamentais e associações de moradores o processo de inclusão social destes grupos permanecia frágil, revelando déficits substantivos nas áreas de educação, trabalho e geração de renda.

Em relação à oferta de serviços de saúde, em 2007 a região de Manguinhos, vinculada à Área Programática 3.1 da Secretaria Municipal de Saúde era coberta pelos profissionais do CSGSF e por 8 equipes da Estratégia Saúde da Família (ESF). Em dezembro de 2008 apenas três equipes estavam completas a partir dos critérios definidos pelo Ministério da Saúde, ou seja, mínimo de um médico, um enfermeiro, um auxiliar de enfermagem e seis agentes comunitários. Além disso, muitas equipes estavam sobrecarregadas sendo responsáveis por um número superior de famílias ao recomendado por área de atuação. No que se refere ao atendimento de média e alta complexidade, apesar das dificuldades de acesso relatadas pelos moradores havia uma oferta razoável, sobretudo comparada à realidade das regiões do interior do país, com destaque para os hospitais Geral de Bonsucesso, Estadual Getúlio Vargas, no bairro da Penha, e Universitário, vinculado à Universidade Federal do Rio de Janeiro (UFRJ) no bairro do Fundão.

Neste cenário, o Fórum Social de Manguinhos marcava o processo recente de revitalização de espaços de mobilização social incorpo- 
rando grupos ligados à academia, gestão e diferentes comunidades. Como um dos desdobramentos das intensas discussões acerca da violência na região, o Fórum foi estruturado em subcomitês a partir dos temas de saneamento, habitação, meio ambiente e saúde, desenvolvimento econômico, trabalho e renda e as reuniões semanais são realizadas na ENSP Fiocruz. A atuação local da ONG Agência 21 e da Pastoral de Favelas e a perspectiva de construção de um Conselho de Desenvolvimento Local também revelam a dinamização da vida associativa local e a tentativa de fortalecer a interlocução entre comunidades e órgãos públicos. A implantação do Programa de Aceleração do Crescimento (PAC), a partir de 2008, com substantivos investimentos previstos para obras de infraestrutura tornou-se tema permanente no âmbito do Fórum reunindo vários representantes dos diferentes níveis de governo, comunidade e pesquisadores da ENSP. Nestas reuniões, um clima de expectativas positivas frente à inauguração do Colégio Estadual Luiz Carlos da Vila com capacidade para 1500 alunos do ensino médio e de uma Unidade de Pronto Atendimento (UPA) - considerada pela secretaria estadual de saúde "a maior do estado", com atendimento 24 horas e articulada a uma "Clínica de Família” com novas equipes do PSF combinavase, muitas vezes, com a desconfiança e ansiedade dos moradores. Uma das questões mais controversas era o deslocamento de famílias cujas casas precisariam ser removidas para a elevação da via férrea e a construção de um parque com equipamentos esportivos e áreas de lazer. O valor das indenizações, considerado baixo pelas famílias e a falta de transparência sobre prazos e abrangência das ações culminaram com a proposta de criação de um conselho intersetorial de acompanhamento do programa.

O programa Bolsa Família em Manguinhos: os limites para a cooperação intersetorial

O programa Bolsa Família foi implantado no município do RJ em junho de 2004, com base na assinatura do Termo de Adesão entre governo federal e prefeitura. A secretaria municipal de Assistência Social (SMAS) através do Núcleo de Transferência de Renda da Subsecretaria de Proteção Social Básica tornou-se o órgão gestor do programa e responsável pela coordenação das atividades de cadastramento e de articulação com as demais secretarias de Educação, Saúde, Habitação, Urbanismo, Esporte e Lazer. Segundo pesquisa realizada pela Escola de Serviço Social da
Universidade Federal do Rio de Janeiro (UFRJ) o protagonismo da área de assistência social no cadastramento e acompanhamento das famílias beneficiárias de programas de transferência de renda alinhava-se às mudanças institucionais previstas na implementação do Sistema Unificado de Assistência Social (SUAS) desde 2003 no país ${ }^{16}$ Através dos "equipamentos de atendimento" ou Centros de Referência da Assistência Social (CRAS) articulados ao SUAS, os vínculos entre o Bolsa Família e a assistência social seriam fortalecidos na direção da garantia de direitos básicos à população mais vulnerável. No entanto, em 2008, os 334 CRAS eram insuficientes para atender cerca de 490 mil famílias beneficiárias em todo o estado.

"O Bolsa Família é um benefício de proteção básica para as famílias cuja entrada deve ser pelo CRAS. Estes devem fazer o encaminhamento para o programa e para as demais ações de renda básica, saúde, educação, trabalho. Hoje não funciona assim, salvo raras exceções" (pesquisadora UFRJ)

Especificamente em Manguinhos, entre 2006 e 2008, a inserção das famílias e a atualização das informações no Cadastro Único (CADUnico) era realizada pelo CRAS Caio Fernando de Abreu, CRAS Nelson Mandela e, também, pelo Centro Especializado de Referência da Assistência Social (CREAS). Segundo a 4a Coordenação de Assistência Social (CAS) responsável pelo acompanhamento dos centros de referência em 2007, dentre as 176 mil famílias cadastradas no RJ, 122 mil eram beneficiárias no município, mas na região de Manguinhos o número de famílias atendidas era impreciso:

"O cadastro é feito a partir do comprovante residencial que, muitas vezes, informa somente parte do endereço e o restante é informado pelo morador. Muitas vezes o bairro informado não corresponde à divisão regional municipal e o nome da comunidade não é informado... fica difícil saber quantas são as famílias nas comunidades do Complexo de Manguinhos" (gestor da assistência social)

De fato, ao longo da pesquisa mapear o número de famílias beneficiárias do programa Bolsa Família em Manguinhos mostrou-se uma tarefa inexequível. Como dito anteriormente, o território desafiava a lógica tradicional de identificação dos moradores, conjugando referências simbólicas e estratégias de localização criadas no cotidiano frente à ausência de arruamento e equipamentos de infraestrutura urbana. O descompasso era permanente e contribuía para a manu- 
tenção de barreiras de acesso não só ao programa Bolsa Família como ao conjunto das políticas públicas. Além disso, a superposição de registros e a dificuldade de comunicação entre os diferentes níveis e agências governamentais colaboravam para a imprecisão em relação à população alvo do programa na região. Sem conhecer o número de famílias inscritas no Bolsa Família perdia-se também a informação estratégica sobre quem eram as crianças fora da escola ou as gestantes que não faziam o acompanhamento do pré-natal nos serviços de saúde.

$\mathrm{O}$ exame, ainda que parcial, do número de famílias atendidas podia ser realizado através dos dados disponibilizados pelas instâncias locais de acompanhamento das condicionalidades da saúde e da educação. Na Secretaria Municipal de Educação o acompanhamento bimestral da frequência escolar dos alunos beneficiários do PBF era realizado pelo Departamento Geral de Educação (DGE). Tal departamento trabalhava articulado com as Coordenadorias Regionais de Educação que eram responsáveis pelo monitoramento dos alunos matriculados nas escolas municipais. A região de Manguinhos está inserida na $4^{\text {a }}$ Coordenadoria Regional de Educação (CRE) e o acompanhamento era realizado no CIEP Juscelino Kubitscheck e nas escolas municipais Profa Maria Cerqueira e Silva, Ema Negrão de Lima e Albino Souza Cruz. O monitoramento da frequência escolar era descentralizado, ou seja, cada escola enviava diretamente ao Ministério da Educação os dados "on line". No entanto, devido a problemas frequentes com as senhas e acesso à internet, um profissional de cada escola, muitas vezes, precisava se deslocar para a $4^{\mathrm{a}} \mathrm{CRE}$ e efetuar a digitação da frequência escolar dos alunos beneficiários. Com relação à gestão das condicionalidades, o programa ficou sob responsabilidade da Coordenação da Rede Básica de Saúde e do Instituto de Nutrição Annes Dias (INAD). Em nível regional, a Coordenação de Área Programática 3.1 tinha acesso "on line" ao sistema de informação relativo ao atendimento de saúde e dessa forma enviava semestralmente os dados sobre as famílias ao Ministério da Saúde. Este sistema deveria possibilitar ao gestor o acesso a informações sobre o número de famílias a serem acompanhadas em cada bairro e o número de famílias acompanhadas em cada unidade de saúde. No entanto, devido a problemas operacionais frequentes durante o desenvolvimento da pesquisa não foi possível obter tais informações.

Ao mesmo tempo, os dados do acompanhamento das condicionalidades da saúde produzi- dos no CSEGSF, que atendia a comunidade de Manguinhos eram, até julho de 2008, consolidados no PAM Maria Cristina Pontes, em Ramos. Ou seja, o serviço de saúde local não conhecia as famílias que deveriam ser monitoradas e, também, não acessava de maneira consolidada a informação sobre os grupos efetivamente atendidos através da demanda espontânea. Com isso, no cotidiano das ações locais de saúde, os profissionais muitas vezes não sabiam informar quantas famílias atendidas deveriam ser acompanhadas ou se haviam descumprido a agenda prevista. Tal dificuldade arrastava-se desde 2006, quando o serviço social do CSEGSF ficou responsável, em parceria com os profissionais da nutrição, pelo acompanhamento das famílias inseridas no programa. Naquele ano, a CAP 3.1 enviou uma listagem com 300 famílias beneficiárias a serem acompanhadas em um prazo determinado. Nesta listagem, muitas famílias não eram moradoras de Manguinhos e a sua localização impôs a ajuda dos agentes comunitários do Programa de Saúde da Família (PSF). A aproximação entre o Bolsa Família e o PSF no nível local através dos agentes comunitários de saúde viabilizou a correção de informações sobre algumas famílias atendidas em Manguinhos, mas, a estratégia desenvolvida concomitantemente ao recadastramento de beneficiários no município gerou apreensão. Para muitos beneficiários a convocação para comparecimento no CSEGSF significava a fiscalização de possíveis irregularidades e, consequentemente, bloqueio do beneficio. Com isso muitos moradores inscritos no programa evitaram atender à solicitação e agentes de saúde sentiram-se constrangidos com a tarefa.

"Foi uma surpresa quando chegou uma planilha com 300 famílias para acompanhar essa condicionalidade. Até então não sabíamos de nada do Bolsa Família..." (assistente social)

Sem qualquer esforço de capacitação e discussão integrada das atividades a serem desenvolvidas, foi grande o "estranhamento" em relação ao programa e acompanhamento das condicionalidades da saúde entre profissionais e técnicos:

"Para que o serviço social? Pesar, medir, avaliar o estado nutricional, a questão da vacina... a gente não sabia direito para que servia essa condicionalidade" (assistente social)

Em parte, tal estranhamento e níveis desiguais de informação entre gestores, profissionais e técnicos no serviço de saúde explicam a escolha por um dia específico na semana - a quinta-feira - para o atendimento dos beneficiários em Manguinhos. A decisão tomada no âmbito do Cen- 
tro de Saúde buscava conjugar o acompanhamento das condicionalidades e atualização de informações exigidas pela secretaria municipal de assistência social e os recursos humanos disponíveis, evitando impactos maiores na rotina e no fluxo das ações de saúde. Embora a solução tenha sido pragmática, de alguma forma, reforçava o estigma em torno dos beneficiários do programa na medida em que eram atendidos separadamente, em um dia da semana. Além disso, a clientela vista como "usuários do Bolsa Família" precisava manter outro agendamento para o atendimento de suas demandas. Gestantes, nutrizes e crianças, que pertenciam às famílias beneficiárias do programa e que já acessavam o centro de saúde para realizar a rotina de pesagem, vacinação e outras ações voltavam na quinta-feira para serem mais uma vez "acompanhadas" no serviço social e nutrição ${ }^{17}$. No início, eram realizadas entrevistas para conhecer melhor as demandas e as necessidades das famílias que chegavam ao serviço de saúde, mas, aos poucos, esta prática se tornou difícil devido ao número reduzido de profissionais. No âmbito local, a burocratização e o paralelismo caminhavam de mãos dadas com a frágil integração intersetorial:

"Era um dia só da semana para fazer o acompanhamento. Filas enormes, 70 atendimentos. As ações ficavam mecânicas, muito burocráticas" (nutricionista)

Neste aspecto, é importante ressaltar que as dificuldades para a cooperação e a integração entre as diferentes agências e secretarias envolvidas no processo de seleção e de cadastramento dos beneficiários, monitoramento das ações e acompanhamento das condicionalidades nos municípios demoraram a ser detectadas pelo governo federal. Somente três anos após a criação do programa, em 2006, é instituído um incentivo financeiro para o fortalecimento da gestão e melhoria da qualidade do cadastramento. A criação do Índice de Gestão Descentralizada (IGD) ${ }^{18}$ através da portaria MDS n.148 buscava assim corrigir a lentidão na atualização dos dados no CadÚnico, melhorar os sistemas de informação locais e estimular o cumprimento das condicionalidades de saúde e educação assim como de programas complementares de geração de renda e trabalho. Os repasses financeiros para a assistência social, educação e saúde estariam, assim, vinculados à capacidade de atingir as metas no que se refere a cadastros novos e atualizados, acompanhamento das ações de saúde e frequência escolar. O IGD também viabilizou a análise dos contornos do programa nos diferentes municípios e pela pri- meira vez a Secretaria Nacional de Renda e Cidadania (SENARC) pôde traçar um panorama das regiões com maiores dificuldades para alcançar os resultados esperados. No entanto, no que se refere à convergência, definição de uma agenda compartilhada e busca solidária de superação de problemas entre os diferentes setores envolvidos na implementação do programa o IGD apresentou pouco ou nenhum resultado.

Como apontam Estrella e Ribeiro ${ }^{19}$ persistem problemas com o fluxo de informações e o risco de perda do repasse, ao invés de trazer ganhos na qualidade das ações, pode incentivar de maneira perversa que os setores registrem de maneira pouco fidedigna o acompanhamento das condicionalidades. O problema pode ser mais grave, particularmente na área da saúde, onde o controle mostrou ser mais difícil devido à superposição de bancos de dados, fragilidade do Sistema de Informação e Vigilância Alimentar e Nutricional (SISVAN) e maior número de procedimentos a serem monitorados. No Rio de Janeiro e em Manguinhos, esta superposição de informações e inconsistência dos dados foram aspectos identificados pelos profissionais e gestores entrevistados:

"O CAD Único não está incorporado em todos os sistemas de informação. É da área social. Eu acompanho o SISVAN, a educação acompanha no sistema da educação e a SMAS na base do CAD Único" (gestor municipal da saúde)

Além da dificuldade para integrar os fluxos de informação, no caso do Rio de Janeiro, o IGD era centralizado na secretaria municipal de assistência social e os demais setores da saúde e educação desconheciam a natureza do incentivo, seus componentes e o montante disponível para apoiar as ações de cada secretaria:

"O recurso do IGD é da secretaria de assistência social. Com o repasse compramos uma Kombi para cada CRAS e para as gerências da secretaria municipal de assistência lotadas na saúde e educação" (gestor municipal da assistência social)

"Eu não sei o que é IGD" (gestor local da área da educação)

"O IGD é administrado pela SMAS. A gente (da saúde) não tem esta discussão" (gestor municipal da saúde)

Para fortalecer a perspectiva de diálogo entre os diferentes setores e níveis de governo envolvidos na execução do programa foram criados o Grupo Intergestor - formado por representantes das secretarias municipais e o Grupo Descentralizado - envolvendo as coordenações regionais de educação, assistência social e educação. 
Em Manguinhos, a $4^{\text {a }}$ Coordenadoria Regional de Educação (CRE), a 4 a Coordenadoria de Assistência Social (CAS) e a Coordenação de Saúde da área programática (CAP 3.1) tornaram-se as principais esferas da estrutura administrativa local do programa. No início, segundo os gestores entrevistados, as reuniões do Grupo Intergestor eram mensais, mas a partir de 2007 tornaram-se cada vez menos frequentes:

"Neste ano não teve reunião do Grupo Intergestor" (gestor municipal da saúde)

Embora a iniciativa apontasse para um esforço de diálogo intersetorial, além da descontinuidade dos encontros o uso dos recursos do IGD não era problematizado:

"O IGD não era discutido nas reuniões do grupo intergestor” (gestor local da área da saúde)

Assim, apesar da existência de espaços de gestão intersetorial institucionalizados no âmbito do programa, a falta de reuniões periódicas e o conhecimento desigual sobre incentivos e critérios de repartição de recursos entre os representantes da assistência social, saúde e educação revelaram as dificuldades ligadas à integração horizontal. Na prática, a principal ação conjunta realizada era o "Dia B", um evento anual criado pelo secretário municipal de assistência social com a proposta de envolver as unidades de saúde municipais, os Centros de Referência de Assistência Social (CRAS) e todos os assistentes sociais municipais que trabalhavam diretamente com a população beneficiária. Divergências sobre os objetivos e alcance do evento eram frequentes:

"O dia B foi uma concepção da Assistência. Para o setor saúde seria um dia de mobilização e divulgação e não de acompanhamento de condicionalidade" (gestor local da área da saúde)

"Trabalhar em parceria é muito difícil. Nem sempre o trabalho técnico corresponde ao tempo político" (gestor local da área da educação)

Apesar da maioria dos gestores entrevistados ressaltar a importância do programa Bolsa Família, era frequente a avaliação de que questões substantivas em relação ao perfil de vulnerabilidade das famílias, aos motivos para o não cumprimento das condicionalidades previstas ou à consistência dos critérios de seleção não eram suficientemente aprofundadas.

"Eu sou professora a noite, trabalho com jovens e adultos. São alunos que eu sei que estão passando fome e não são contemplados. A gente não sabe por que, parece que há uma roleta no MEC para escolher aleatoriamente. Infelizmente não são as mais vulneráveis que são contempladas. Três pessoas atendendo o critério, duas re- cebem e uma não recebe" (gestor municipal da educação)

\section{A articulação entre o programa Bolsa Família e a Estratégia Saúde da Família: a tentativa de compartilhar diagnósticos e responsabilidades}

A estratégia Saúde da Família em Manguinhos, apesar de contar com o chamado "Grupo de Apoio Técnico" (GAT) na CAP 3.1 voltado à supervisão das ações locais de atenção básica, pouco interagiu com o processo de implementação do programa Bolsa Família até meados de 2008. Como vimos, inicialmente apenas os agentes comunitários de saúde desenvolveram atividades conjuntas, ainda que basicamente direcionadas à localização das famílias beneficiárias. Podemos dizer que, em Manguinhos, as equipes do PSF não participavam das ações de saúde do programa Bolsa Família. Somente em junho deste mesmo ano as oito equipes do PSF foram envolvidas no acompanhamento das condicionalidades da saúde na área de abrangência do CSGSF.

As dificuldades ligadas à rotatividade de profissionais, sobretudo de médicos e enfermeiros, e a relação entre o CSEGSF e a estrutura administrativa e organizacional do PSF no município contribuíram para os laços frágeis entre os dois programas. A superposição de atividades e de registros de atendimento gerava críticas e, assim, a coordenação do PSF local decidiu incluir o acompanhamento das famílias beneficiárias do Bolsa Família na rotina de visitação das equipes. Neste processo de transição, as informações colhidas pela assistente social e pela nutricionista foram repassadas aos profissionais do PSF e um treinamento voltado aos agentes comunitários de saúde foi iniciado. Embora o CSEGSF ainda não participasse das reuniões organizadas pela coordenação da área programática (CAP 3.1) e desconhecesse a conformação da listagem de beneficiários do Bolsa Família, enviada pela secretaria municipal de saúde à divisão de responsabilidades, foi aos poucos se tornando mais cotidiana. Ao mesmo tempo, através do diálogo com núcleos de pesquisa interessados em avançar na espacialização, geoprocessamento e melhoria da qualidade dos dados sobre os moradores da área 24, o CSEGSF desenvolveu novas estratégias voltadas à convergência de ações de promoção da saúde e ao desenvolvimento de iniciativas comunitárias. Nas fichas de acompanhamento Sistema de Atenção Básica (SIAB) a informação sobre a inserção no programa Bolsa Família passou a inte- 
grar o conjunto de dados coletados permitindo a sistematização das informações sobre a cobertura do programa Bolsa Família em Manguinhos. Sem dúvida, a articulação entre os programas rumo a uma troca permanente de informação e cooperação entre os agentes implementadores locais começava a dar os primeiros passos.

\section{Resultados e discussão}

A transferência de renda para as famílias pobres sem que existam caminhos claros para a inserção social a longo prazo reforça opções conservadoras e assistencialistas. Experiências bem sucedidas em vários países mostram que tais programas devem buscar reforçar laços com o conjunto de ações de proteção social e desenvolvimento local. Um modelo de proteção social baseado apenas em uma perspectiva "indenizatória”20 é incapaz de recriar circuitos de integração e reduzir a incerteza e a instabilidade presentes nas situações de vulnerabilidade social contemporâneas. As transformações no mercado de trabalho e a exigência de novas competências e habilidades tornam a educação e a capacitação profissional questões decisivas para a maior efetividade das políticas de combate à pobreza. Considerando que, no Brasil os índices de repetição são altos - $18 \%$ na faixa etária de 7 a 14 anos e $26 \%$ entre 10 a 14 anos $^{21}$ - a falta de incentivos para a progressão escolar no programa Bolsa Família revela que há pouco consenso sobre quais são os componentes estratégicos para a atuação governamental na área.

No caso de Manguinhos, onde persistem profundos déficits educacionais e, consequentemente, chances mais reduzidas de empregabilidade é importante associar ao Bolsa Família esforços voltados à expansão de capacidades e oportunidades ocupacionais compatíveis com a realidade local. Durante a pesquisa, foi possível perceber a fragilidade dos programas complementares ou ações de geração de trabalho e renda voltados aos beneficiários do programa Bolsa Família. Tais iniciativas, uma vez dinamizadas possibilitam efeitos a longo prazo no que se refere à superação da pobreza e podem dar resposta à heterogeneidade das situações de privação. A maioria dos gestores e profissionais entrevistados desconheciam ações nesta direção. Nos debates no âmbito do Fórum Social de Manguinhos, tampouco as ações e o escopo do programa Bolsa Família assumiam, no decorrer da pesquisa, espaços privilegiados. É importante ressaltar que a maior articulação entre as intervenções voltadas à redução da pobreza e a inserção social e a dinâmica associativa local pode ter efeitos extremamente positivos no que se refere à equidade. Dificilmente apenas as agências governamentais isoladamente podem agregar os recursos e as redes de apoio e confiança necessários para intervir nos quadros e problemas complexos dos campos da saúde e da proteção social ${ }^{22}$. A inclusão de "mecanismos de validação comunitária”, seja nos fluxos de cadastramento de beneficiários, nas práticas desenvolvidas pelos diferentes profissionais envolvidos ou ainda no desenho de iniciativas locais articuladas a programas sociais, pode contornar o déficit de informações qualificadas sobre necessidades e demandas da população. $\mathrm{O}$ fortalecimento de coalizões envolvendo lideranças comunitárias, profissionais, técnicos e gestores locais em torno do programa é crucial. Vários autores têm chamado a atenção para a importância da colaboração entre profissionais e lideranças comunitárias para a maior sustentabilidade das políticas públicas ${ }^{23}$.

No que se refere ao fortalecimento de ações intersetoriais ligadas ao Bolsa Família, a qualidade e o fluxo de informações entre os diferentes agentes implementadores locais foram aspectos chave. Na experiência de Manguinhos o conhecimento dos efeitos e as repercussões do programa esbarrava permanentemente na dificuldade para acompanhar as famílias beneficiárias e consolidar dados relevantes. Ainda que não seja tarefa fácil associar mudanças positivas nas condições de saúde e educação a programas de transferência de renda, o esforço de monitoramento permanente e longitudinal das famílias inseridas em programas de transferência condicionada de renda é fundamental para a avaliação de resultados, impactos e alcances das ações. Tais informações também se mostram importantes para a consolidação de estratégias de cooperação, adoção de alternativas novas e articulação entre setores. A ausência de uma "cultura de sistematização de evidências" dificulta o aprendizado institucional e diminui a possibilidade de mudanças na gestão local. Segundo Pawson ${ }^{24}$ os bons resultados de um programa dependem tanto da manutenção das estratégias bem sucedidas como da capacidade de evitar a repetição dos mesmos erros. Mas como ter clareza sobre erros e acertos se os sistemas de informação são superpostos, descontinuados ou exigem maiores investimentos em equipamentos e capacitação técnica? Ao mesmo tempo, a ênfase na coleta de dados sem a preocupação com a tradução e utilização da in- 
formação no processo de implementação das ações não contribui para a orientação estratégica de gestores e agentes implementadores locais.

As dificuldades para o avanço da articulação intersetorial também estiveram associadas à falta de clareza em relação aos critérios para o repasse de recursos ou desconhecimento sobre a existência de um incentivo para a gestão descentralizada do programa Bolsa Família. No caso da gestão do IGD no município do RJ, a centralização no âmbito da secretaria de assistência social - em tese um setor que tem o mesmo nível hierárquico que as demais secretarias de educação e saúde - pode dificultar a construção de pactos e compromissos. Torna-se mesmo paradoxal a conformação de espaços de concertação e interlocução como o Grupo Intergestor sem que todos os setores envolvidos tenham possibilidade de influenciar as decisões sobre o uso dos recursos previstos no IGD.

\section{Conclusão}

Como apontam Pluye et al..$^{25}$ pouco se sabe sobre os processos que levam à maior sustentabilidade dos programas, definida como a consolidação e continuidade das atividades e do fluxo de recursos, para o alcance dos objetivos propostos. No entanto, um programa para ser considerado sustentável, segundo os autores, deve estar integrado à rotina organizacional e ao per- fil institucional das políticas públicas em um determinado contexto. Ao mesmo tempo, a sustentabilidade de uma intervenção não significa imobilismo, mas sim uma perspectiva de longo prazo que integra esforços de readaptação e possíveis "mudanças de rota". Em Manguinhos, a articulação entre o programa Bolsa Família e a estratégia Saúde da Família assinala um caminho potencialmente rico para a consolidação de ações intersetoriais. Como analisam Viana e Fon$\mathrm{seca}^{26}$, o processo de interação entre o Bolsa $\mathrm{Fa}$ mília e a estratégia de Saúde da Família potencializa o efeito sinérgico entre ações de combate a pobreza e expansão da atenção básica. $\mathrm{O}$ apoio das equipes de saúde da família "desvendando" a região de Manguinhos gera avanços no processo de identificação dos beneficiários do Bolsa Família, possibilita o reconhecimento das distintas situações de vulnerabilidade, amplia o acesso aos serviços de saúde e favorece o estreitamento dos vínculos entre o programa e as demais políticas públicas. A maior aproximação e a interdependência entre as ações do PAC, PSF e Bolsa Família na região podem, assim, fortalecer "policy networks" e ações multiestratégicas frente à pobreza e exclusão social no contexto local. Com isso, a perspectiva da intervenção segmentada e alheia à realidade dos que não conseguem romper as profundas barreiras sociais, que impedem o acesso a equipamentos públicos, pode dar lugar à convergência de ações e mudanças efetivas.

\section{Colaboradores}

R Magalhães, AV Coelho, MF Nogueira e C Bocca participaram igualmente de todas as etapas da elaboração do artigo. 


\section{Referências}

1. Brasil. Ministério do Desenvolvimento Social (MDS) Decreto 5.209 de 17 de setembro de 2004. Regulamenta a Lei no 10.836, de 9 de janeiro de 2004, que cria o Programa Bolsa Família e dá outras providências. Diário Oficial da União 2004; 17 set.

2. Brasil. Ministério do Desenvolvimento Social e Combate à Fome. [homepage na internet]. Brasília: MDS [acessado 2008 mai 15]. Disponível em: http:/ /www.desenvolvimentosocial.gov.br/mds/_htm/ ministerio.shtm

3. Marques RM, Mendes A, Leite MG, Hutz, A. A importância do Bolsa Família nos municípios brasileiros. In: Cadernos de Estudos Desenvolvimento Social em Debate $n^{\circ}$ 1. Brasília: Ministério Desenvolvimento Social e Combate à Fome; 2005

4. Rocha S. A Pobreza no Brasil, Afinal do que se trata? Rio de Janeiro: FGV Editora; 2003.

5. Schwartzman S. Programas Sociais voltados a Educação no Brasil. Sinais Sociais 2006; 1(1):114-144

6. Magalhães R, Burlandy L, Senna M, Schotz V, Scalercio, G. O Programa Bolsa Família no estado do RJ: as experiências de São Francisco de Itabapoana e Duque de Caxias. Cien Saude Colet 2007; 12(6):15131524 .

7. Instituto Brasileiro de Análises Sociais e Econômicas (IBASE). Repercussões do Programa Bolsa Família na Segurança Alimentar e Nutricional das Famílias Beneficiadas [Documento Síntese]. Rio de Janeiro: IBASE; 2008

8. Patton MQ. From evaluation issues to evaluation models. In: Patton MQ. Qualitative research \& evaluation methods. $3^{\text {a }}$ ed. London: Sage Publications; 2002.

9. Pressman JL, Widalski A. Implementation. Berkeley: University of California Press; 1984.

10. Pawson R. Evidence-based policy: the promise of realist synthesis. London: Sage; 2002.

11. Yin RK. Estudo de Caso: Planejamento e Métodos. Porto Alegre: Bookman; 2005.

12. Junqueira LAP. Intersetorialidade, transetorialidade e redes sociais de saúde. Rev Adm. Pública 2000 34(6):35-45.

13. Instituto Brasileiro de Geografia e Estatística (IBGE). Brasil: Censo Demográfico 2000. Rio de Janeiro: IBGE; 2000.

14. Instituto Pereira Passos (IPP). Armazém de Dados, Portal, 2007. [acessado 2007 maio 15]. Disponível em: http://www.armazemdedados.rj.gov.br

15. Bodstein R, Zancan L, Estrada DD, organizadores. Guia de equipamentos e iniciativas sociais. Rio de Janeiro: Editora Fiocruz; 2001.
16. Coelho AVO. Desafio da Intersetorialidade na Implementação do Programa Bolsa Família em Manguinhos [dissertação]. Rio de Janeiro: ENSP, Fiocruz; 2009.

17. Ferreira MN. Programas de Transferência Condicionada de Renda e Acesso aos Serviços de Saúde [dissertação]. Rio de Janeiro: ENSP, Fiocruz; 2009.

18. Brasil. Ministério do Desenvolvimento Social e Combate à Fome. Portaria n.148 de 27 de abril de 2006. Estabelece normas, critérios e procedimentos para o apoio à gestão do Programa Bolsa Família e do Cadastro único dos Programas Sociais do Governo Federal no âmbito dos municípios e cria o Índice de Gestão Descentralizada do Programa. Diário Oficial da União 2006; 28 abr.

19. Estrella J, Ribeiro LM. Qualidade da gestão das condicionalidades do programa Bolsa Família: uma discussão sobre o Índice de Gestão Descentralizada. Rev Adm. Pública 2008; 42(3):625-641.

20. Fitoussi JP, Rosanvallon P. Le Nouvel Âge dês Inegalités. Paris: Seuil; 1996.

21. Instituto Brasileiro de Geografia e Estatística (IBGE). Pesquisa Nacional de Amostra de Domicílios (PNAD), 2004. [acessado 2008 maio 15]. Disponível em: http:/ /www. ibge.gov.br

22. Bodstein R. The complexity of the discussion on effectiveness and evidence in health promotion practices. Promot Educ 2007; (Supl. 1):16-20.

23. Burris S, Hancock T, Lin V, Herzog A. Emerging Strategies for Healthy Urban Governance. Journal of Urban Health 2007; 84(1):154-163.

24. Pawson R. Evidence-based policy: the promise of realist synthesis. London: Sage; 2002.

25. Pluye P, Potvin L, Denis JL. Making public health programs last: conceptualizing sustainability. Eval Program Plann 2004; 27:121-133.

26. Viana ALA, Fonseca A. Direito a saúde, atenção básica e transferências condicionadas de renda na América Latina. Cien Saude Colet 2007; 12(6):15051512.

Artigo apresentado em 28/03/2010

Aprovado em 02/05/2010

Versão final apresentada em 10/05/2010 
